\title{
Terminação de novilhos Nelore, castrados e não castrados, em confinamento com dieta alto grão
}

\section{Finishing of Nellore steers, castrated and no-castrated, in feedlot diet with high-grain}

\author{
DIAS, Alexandre Menezes ${ }^{1 *}$; OLIVEIRA, Leonardo Batista de ${ }^{1}$; ÍTAVO, Luís Carlos \\ Vinhas ${ }^{1}$; MATEUS, Rogério Gonçalves ${ }^{1}$; GOMES, Eva Nara Oliveira ${ }^{1}$; COCA, \\ Fabiane Ortiz do Carmo Gomes ${ }^{1}$; ÍTAVO, Camila Celeste Brandão Ferreira ${ }^{1}$; \\ NOGUEIRA, Ériklis ${ }^{2}$; MENEZES, Bruna Biava de ${ }^{1}$; MATEUS, Rodrigo Gonçalves ${ }^{3}$
}

\footnotetext{
${ }^{1}$ Universidade Federal de Mato Grosso do Sul, Faculdade de Medicina Veterinária e Zootecnia, Programa de Pós-Graduação em Ciência Animal, Campo Grande, Mato Grosso do Sul, Brasil;

${ }^{2}$ Embrapa Pantanal, Corumbá, Mato Grosso do Sul, Brasil.

${ }^{3}$ Universidade Católica Dom Bosco, Curso de Zootecnia, Campo Grande, Mato Grosso do Sul, Brasil;

*Endereço para correspondência: alexandre.menezes@ufms.br
}

\section{RESUMO}

Objetivou-se avaliar a terminação de novilhos Nelore, castrados e não castrados, em confinamento recebendo dieta alto grão, por meio do consumo de nutrientes, desempenho produtivo e viabilidade econômica da dieta. Foram utilizados 180 animais da raça Nelore, distribuídos em dois tratamentos (castrados e não castrados), com 90 animais por tratamento, com peso médio inicial de $415,64 \mathrm{~kg}$, recebendo dieta alto grão, constituída de $85 \%$ de milho grão e $15 \%$ de núcleo mineral-proteicoenergético. O período experimental foi de 63 dias, sendo 15 dias para adaptação as dietas e 48 dias de confinamento. Houve efeito significativo para os consumos de nutrientes $(\mathrm{P}<0,05)$, apresentando médias de consumos de matéria seca de 7,60 e 7,96kg para animais castrados e não castrados. Houve efeito para as variáveis de desempenho produtivo em função da classe sexual (castrado e não castrado). Os animais não castrados apresentaram maiores $(\mathrm{P}<0,05)$ peso de abate, ganho de peso, peso de carcaça quente, rendimento de carcaça e melhor conversão alimentar quando comparados aos animais castrados terminados em confinamento recebendo dieta alto grão. Os animais castrados apresentaram maior espessura de gordura que os animais não castrados, de 4,80 e 3,40mm, respectivamente. Os animais não castrados apresentaram margem de lucro/animal de $\mathrm{R} \$$ 256,00 e os castrados de R\$ 202,80. Recomenda-se a terminação de novilhos Nelore em confinamento recebendo dieta alto grão. Os animais não castrados apresentaram maior ganho de peso e lucro no sistema de terminação em confinamento recebendo dieta alto grão.

Palavras-chave: classe sexual, ganho de peso, produção animal, ruminantes

\section{SUMMARY}

This study aimed to evaluate the finishing Nellore steers castrated and no-castrated in feedlot receiving high-grain diet through the nutrients intake, productive performance and economic viability of the diet. 180 Nellore animals were divided into two treatments (castrated and no-castrated), with 90 animals per treatments, with an average initial weight of $415.64 \mathrm{~kg}$, receiving high-grain diet with $85 \%$ corn grain and $15 \%$ supplement mineralprotein-energy. The experimental period was 63 days with 15 days for adaptation diets and 48 days of feedlot. Was no significant effect on intake of nutrients $(\mathrm{P}<0.05)$, presenting a mean intake of dry matter (DM) of 7.60 and $7.96 \mathrm{~kg}$ for castrated and no-castrated. Effects were observed for productive performance as a function of sex condition (castrated and nocastrated). The not castrated animals had higher $(\mathrm{P}<0.05)$ slaughter weight, total weight gain, hot carcass weight, carcass yield and better feed conversion when compared to castrated animals finished in feedlot receiving high-grain diet. 
Castrated animals have a higher fat thickness that animals no-castrated, 4.80 and $3.40 \mathrm{~mm}$, respectively. The no-castrated animals showed profit margin lucre/animal of $\mathrm{R} \$ 256.00$ and $\mathrm{R} \$$ 202.80 for castrated. Receiving the termination of Nellore steers in a feedlot is recommended high-grain diet. The no-castrated animals showed greater weight gain and profit in the feedlot finishing system receiving high-grain diet.

Keywords: animal production, ruminants, sexual condition, weight gain

\section{INTRODUÇÃO}

No Brasil o abate de bovinos não castrados vem sendo utilizada, porém é necessário que alternativas de alimentação sejam utilizadas para que esses animais, no momento do abate venham atender as exigências dos frigoríficos visando melhorar a deposição de gordura na carcaça e o manejo dos animais pré-abate. A castração apresenta algumas vantagens relacionadas com o melhor manejo do gado, com a lucratividade do sistema e com a maior aceitação do produto pelo mercado, (ÍTAVO et al., 2008).

Avaliando bovinos Nelore, castrados e não castrados, Silva et al. (2008) verificaram que quando terminados em confinamento por 50 dias os animais não castrados apresentam maior ganho de peso e rendimento de carcaça e para que os animais melhorem o acabamento da carcaça é necessário que a dieta dos animais seja balanceada com maior nível energético. Segundo Paulino et al. (2009) pouco se conhece sobre os efeitos de classe sexual e nível energético da dieta, bem como sua interação, sobre o crescimento e a composição corporal de bovinos Nelore no Brasil.

A pecuária de corte brasileira vem passando por um processo de intensificação, em busca do crescimento da taxa de desfrute do rebanho, em função disso, a prática de terminação de animais confinados vem crescendo consideravelmente nos últimos anos (OBEID et al., 2006). Com isso, a implantação do sistema de confinamento pode levar a um alívio da pressão de pastejo, principalmente na época seca do ano em que as pastagens possuem uma baixa qualidade nutricional.

A dieta alto grão sem volumoso possibilita ao sistema do confinamento um máximo ganho de peso individual, proporciona a produção de animais precoces e permite uma padronização no lote. O que torna o sistema vantajoso e de fácil implantação é a ausência do fornecimento de volumoso, pois reduz o manejo pelos funcionários e os gastos que envolvem a produção e o armazenamento de um alimento volumoso em uma propriedade.

O que irá determinar a eficiência do sistema será a aquisição do milho grão e o preço pago pela arroba. Conhecer o custo da dieta na terminação de bovinos em confinamento é de fundamental importância para que o pecuarista possa decidir sobre a alocação de recursos visando obter maior competitividade no setor.

É preciso levar em consideração alguns fatores que influenciam nos custos do sistema de terminação em confinamento como a aquisição dos animais e alimentos para formulação da dieta. Assim, objetivou-se avaliar a terminação de novilhos Nelore, castrados e não castrados, recebendo dieta alto grão em confinamento, por meio do consumo de nutrientes, desempenho produtivo $\mathrm{e}$ viabilidade econômica da dieta. 


\section{MATERIAL E MÉTODOS}

O experimento foi realizado na Fazenda Guarani, situada no município de Sidrolândia - MS, e na Faculdade de Medicina Veterinária e Zootecnia (FAMEZ) da Universidade Federal de Mato Grosso do Sul.

Foram utilizados 180 novilhos, da raça Nelore, sendo 90 animais castrados e 90 não castrados com idade média de 28 meses e peso corporal (PC) médio inicial de $415,64 \mathrm{~kg}$. Os tratamentos foram distribuídos em delineamento inteiramente casualizado, com dois tratamentos, animais castrados e não castrados, com 90 animais por tratamento. Os animais foram distribuídos em seis baias, sendo 30 animais/baia. O período experimental foi de 63 dias, sendo 15 dias para adaptação dos animais a dieta e 48 dias de coleta de dados.

Os animais foram alocados em baias coletivas de chão batido, sendo que a área ocupada no confinamento por animal foi de $20 \mathrm{~m}^{2}$ /animal. Os cochos foram de galões de plástico de 200 litros partidos ao meio.

Foram realizadas quatro pesagens, sendo a primeira no inicio da adaptação, a segunda no inicio do confinamento, a terceira pesagem foi aos 24 dias e a quarta pesagem aos 48 dias, em jejum de sólidos por 16 horas.

As dietas eram compostas de milho grão e núcleo mineral-proteico-vitamínico na proporção de $850,0 \mathrm{~g} / \mathrm{kg}$ de milho grão inteiro e $150,0 \mathrm{~g} / \mathrm{kg}$ de núcleo mineralproteico-energético (Tabela 1). Foram realizadas análises bromatológicas da dieta, determinando os teores de matéria seca (MS), matéria orgânica (MO), matéria mineral $(\mathrm{MM})$, proteína bruta (PB), extrato etéreo (EE), fibra em detergente neutro (FDN) e fibra em detergente ácido (FDA) conforme descrito em Silva \& Queiroz (2002). Os teores de nutrientes digestíveis totais estimado (NDT est) foram calculados segundo Capelle et al. (2001) com a equação para dieta total (NDT est $=$ $91,0246-0,571588 * \mathrm{FDN})$.

Tabela 1. Composição química dos ingredientes e da dieta experimental

\begin{tabular}{lccc}
\hline Item & Milho grão & Núcleo & Dieta \\
\hline Matéria seca (g/kg) & 862,00 & 880,0 & 864,70 \\
Matéria orgânica (\% da MS) & 833,00 & 580,0 & 795,10 \\
Proteína bruta (g/kg da MS) & 91,00 & 360,00 & 131,30 \\
Extrato etéreo (g/kg da MS) & 51,00 & 27,00 & 47,40 \\
Fibra em detergente neutro (g/kg da MS) & 95,00 & 25,00 & 118,30 \\
Matéria mineral (g/kg da MS) & 29,00 & 293,00 & 68,60 \\
NDT est (g/kg da MS) & 855,90 & 767,30 & 843,90 \\
Digestibilidade in vitro da MS (g/kg) & 844,00 & 700,00 & 822,20 \\
\hline MS = matéria seca; composição do núcleo: cálcio = 40,00 g/kg; fósforo = 7,61 g/kg; enxofre $=10,35$ \\
g/kg; sódio = 7,85 g/kg; zinco = 300 mg/kg; vitamina A = 11560 UI/kg; vitamina D = 3400 UI/kg; \\
vitamina E = 57,8 UI/kg; salinomicina = 110 mg; virginiamicina = 229,5 mg; Dieta = 85\% de milho \\
grão inteiro + 15\% de núcleo mineral-proteico-energético; NDT est = nutrientes digestíveis totais \\
estimado.
\end{tabular}

Os animais passaram por um período de 15 dias de adaptação em piquetes de Brachiaria brizantha cv. Marandu de
0,35 hectares, onde a ração foi fornecida e aumentada a cada três dias de acordo com o peso corporal (PC) dos animais. 
Nos três primeiros dias, recebiam $1 \%$ do seu PC de ração na matéria natural, e a cada três dias foram aumentados $0,2 \%$ de ração em proporção ao seu PC inicial, no $15^{\circ}$ dia os animais já estavam consumindo $2,0 \%$ do $\mathrm{PC}$ de ração na matéria natural. No $16^{\circ}$ dia os animais foram pesados e distribuídos nas baias em seus respectivos tratamentos, onde permaneceram até o abate.

O fornecimento da dieta foi ad libitum, com o ajuste para $10 \%$ de sobras, realizados em três tratos diários, às $8 \mathrm{~h}$, $12 \mathrm{~h}$ e $16 \mathrm{~h}$. O fornecimento de água foi $\mathrm{ad}$ libitum em bebedouros de concreto de 1000 litros de água para as duas baias.

$\mathrm{O}$ ganho de peso total (GPT) foi calculado pelo ganho de peso dos animais por 48 dias de confinamento. O Ganho médio diário (GMD), em $\mathrm{kg} / \mathrm{dia}$, foi calculado da seguinte forma: GMD = (PA-PC inicial)/63 dias.

O Peso de carcaça quente (PCQ), em kg, foi tomado no frigorífico logo após abate dos animais, antecedendo o resfriamento da carcaça. Após 48 dias, de confinamento, os animais foram abatidos em frigorífico comercial, com o valor da arroba (@) de R\$105,00. O peso de abate (PA) foi tomado na propriedade antes do embarque para o frigorífico, em jejum de sólidos por $16 \mathrm{~h}$. Para a avaliação das características de carcaça, o abate foi realizado em frigorífico industrial. $\mathrm{O}$ rendimento de carcaça ( $\mathrm{RC}$ ) foi calculado com o peso de abate (PA) anotado na propriedade antes do embarque e o peso de carcaça quente, de acordo com o romaneio do frigorífico, ou seja, RC $=$ PCQ $(\mathrm{kg}) / \mathrm{PA}(\mathrm{kg}))^{*} 100$. Entre a $12^{\mathrm{a}} \mathrm{e}$ $13^{\mathrm{a}}$ costela, realizou-se um corte horizontal visando expor o músculo Longíssimus dorsi e realizada a medição da espessura de gordura subcutânea (mm) obtida pela média de duas observações.

A conversão alimentar (CA) foi determinado pelo consumo de matéria seca (CMS) diário em $\mathrm{kg} /$ dia pelo GMD em kg/dia (CMS dia/GMD).

$\mathrm{O}$ preço de aquisição dos animais praticado no momento de compra dos animais foi de $\mathrm{R} \$ 3,38 / \mathrm{kg}$ do PC. O preço do milho grão inteiro praticado foi de $\mathrm{R} \$$ $0,27 / \mathrm{kg}$. O preço $/ \mathrm{kg}$ do núcleo grão inteiro foi de $\mathrm{R} \$ 1,25$.

Os dados foram submetidos à análise de variância e as médias comparadas pelo teste Tukey a $5 \%$ de probabilidade.

\section{RESULTADOS E DISCUSSÕES}

Houve efeito da castração no consumo (Tabela 2) de nutrientes em $\mathrm{kg} /$ dia. Os animais não castrados apresentam maiores consumos de MS, MO, FDN e NDT $(\mathrm{P}<0,05)$, quando comparados aos animais castrados. Este aumento no consumo pode estar correlacionado a maior CA e GMD (Tabela 3) dos animais não castrados, visto que $\mathrm{o}$ consumo em \% do $\mathrm{PC}(\mathrm{P}>0,05)$ não foi significativo (Tabela 2). $\mathrm{O}$ tamanho corporal influencia no consumo, o que possibilita maior consumo para animais mais pesados, o que proporcionou maior consumo de MS por parte dos animais não castrado.

Os animais não castrados apresentaram consumo de NDT $4,73 \%$ a mais que os animais castrados. De acordo com o NRC (1996), machos não castrados demandam $15 \%$ a mais de energia para mantença que os castrados. Animais não castrados da raça zebuína demandam maior exigência de nutrientes para mantença e ganho de peso (VALADARES et al., 2006). O consumo da dieta é influenciado pelo peso corporal do animal, apresentando assim maior exigência de mantença, o que refletirá no consumo de nutrientes da dieta. Segundo McDonald et al. (1995), o peso é o principal 
Rev. Bras. Saúde Prod. Anim., Salvador, v.17, n.1, p.45-54 jan./mar., $2016 \quad$ http://www.rbspa.ufba.br ISSN 15199940

determinante da composição corporal e das exigências nutricionais para crescimento.

As dietas com altos níveis de concentrado podem gerar algumas variações comportamentais dos animais, como menor tempo de alimentação e de ruminação, o que leva a um aumento no tempo de ócio (MISSIO et al., 2010). No entanto, tal efeito pode ser minimizado quando se aumenta a frequência de fornecimento da dieta e uma boa adaptação à dieta alto grão. Além de proporcionar uma redução de possíveis acidoses, visto que este manejo reduz os altos picos de ácidos produzidos durante a fermentação no rúmen. Não foram observados sinais clínicos de acidose ou laminite nos animais durante o período experimental.

Tabela 2. Consumos de nutrientes, em $\mathrm{kg} / \mathrm{dia}(\% \mathrm{MS})$ e em $\%$ do peso corporal (\% PC), de novilhos Nelore, castrados e não castrados, terminados em confinamento recebendo dieta alto grão

\begin{tabular}{|c|c|c|c|c|}
\hline \multirow{2}{*}{ Variável } & \multicolumn{2}{|c|}{ Classe sexual } & \multirow{2}{*}{$\mathrm{CV}$} & \multirow{2}{*}{$\mathrm{P}$} \\
\hline & Castrado & Não Castrado & & \\
\hline \multicolumn{5}{|c|}{ Consumo Kg/dia } \\
\hline Matéria seca & 7,60 & 7,96 & 4,03 & 0,001 \\
\hline Matéria orgânica (\% MS) & 6,04 & 6,32 & 4,19 & 0,001 \\
\hline Proteína bruta (\% MS) & 1,15 & 1,21 & 4,22 & 0,001 \\
\hline Extrato etéreo (\% MS) & 0,42 & 0,44 & 2,23 & 0,215 \\
\hline Fibra em detergente neutro (\% MS) & 1,04 & 1,09 & 4,19 & 0,001 \\
\hline Nutrientes digestíveis totais (\% MS) & 7,42 & 7,76 & 7,02 & 0,003 \\
\hline \multicolumn{5}{|c|}{ Consumo \% PC } \\
\hline Matéria seca & 1,68 & 1,70 & 4,03 & 0,223 \\
\hline Matéria orgânica & 1,34 & 1,35 & 4,19 & 0,223 \\
\hline Proteína bruta & 0,26 & 0,26 & 4,22 & 0,325 \\
\hline Extrato etéreo & 0,09 & 0,09 & 2,23 & 0,215 \\
\hline Fibra em detergente neutro & 0,23 & 0,23 & 4,19 & 0,365 \\
\hline Nutrientes digestíveis totais & 1,64 & 1,66 & 7,02 & 0,268 \\
\hline
\end{tabular}

$\mathrm{CV}=$ coeficiente de variação; $\mathrm{P}=$ nível de significância.

Proporção dos ingredientes da dieta: $85 \%$ de milho grão e $15 \%$ de núcleo.

Os animais não castrados apresentaram maior peso de abate (PA), ganho de peso total (GPT), ganho médio diário (GMD), peso de carcaça quente (PCQ), rendimento de carcaça (RC), melhor conversão alimentar (CA) e peso em arrobas (@) produzidas, quando comparados aos animais castrados terminados em confinamento recebendo dieta alto grão (Tabela 3).

Os animais não castrados apresentaram uma taxa de crescimento de 16,28\% superior em relação aos castrados. Resultados de pesquisa mostraram que animais não castrados crescem mais rapidamente e utilizaram o alimento mais eficientemente que os animais castrados (FIELD, 1971). Silva et al. (2008) verificaram que animais não castrados apresentaram maior GMD $(1,42$ e $1,15 \mathrm{~kg})$ que os castrados, apresentando uma taxa de crescimento de 23,48\%. Marcondes et al. (2008) relataram que Machos Nelore nãocastrados ganham $24 \%$ a mais de peso que machos castrados. A classe sexual é um dos fatores determinantes da composição do ganho de peso, devido à influência da ação hormonal 
favorecendo maior ganho de peso devido a maior deposição de músculo.

Para a variável de conversão alimentar os animais não castrados foram $11,11 \%$ mais eficientes que os animais castrados. Os animais não castrados apresentaram melhor conversão alimentar $(\mathrm{kg}$ consumido/kg de ganho) que os animais castrados, o que corrobora com Restle et al. (1997) onde os autores demonstraram a superioridade do desempenho de animais não castrados. Isto pode estar relacionado ao fato de que a produção hormonal proveniente dos testículos dos animais não castrados tenha apresentado maior efeito na deposição de músculo na fase de crescimento. Verifica-se assim a importância do hormônio testosterona não só no ganho de peso, mas também na conversão alimentar.

Tabela 3. Desempenho produtivo e características de carcaça de bovinos Nelore, castrado e não castrado, terminados em confinamento, recebendo dieta alto grão

\begin{tabular}{|c|c|c|c|c|}
\hline \multirow{2}{*}{ Variável } & \multicolumn{2}{|c|}{ Classe sexual } & \multirow{2}{*}{$\mathrm{CV}$} & \multirow{2}{*}{$\mathrm{P}$} \\
\hline & Castrado & Não Castrado & & \\
\hline Peso Corporal inicial (kg) & 411,07 & 420,20 & 19,60 & 0,986 \\
\hline Peso de Abate $(\mathrm{kg})$ & 494,34 & 514,59 & 16,07 & 0,001 \\
\hline Ganho de peso total $(\mathrm{kg})$ & 81,27 & 94,39 & 5,46 & 0,001 \\
\hline Ganho médio diário $(\mathrm{kg} / \mathrm{dia})$ & 1,29 & 1,50 & 5,46 & 0,001 \\
\hline Rendimento de carcaça (\%) & 52,67 & 53,23 & 4,12 & 0,001 \\
\hline Peso de carcaça quente $(\mathrm{kg})$ & 260,37 & 273,92 & 4,12 & 0,001 \\
\hline Espessura de Gordura Subcutânea (mm) & 4,80 & 3,40 & 18,05 & 0,006 \\
\hline Conversão alimentar & 5,90 & 5,31 & 3,52 & 0,001 \\
\hline Peso em Arrobas (@) & 17,36 & 18,26 & 4,52 & 0,001 \\
\hline
\end{tabular}

Conversão alimentar $=$ CMS diário/GMD.

Os ganhos de peso dos animais não castrados foram superiores aos castrados o que proporcionou maior peso de abate, consequentemente devido a maior deposição de tecido muscular. Segundo Paulino et al. (2009) bovinos machos não castrados depositam proteína de forma mais pronunciada no corpo vazio em comparação a machos castrados. Porém os animais castrados apresentaram maior espessura de gordura subcutânea, proporcionando melhor acabamento de gordura que os animais não castrados (Tabela 3).

Os animais não castrados obtiveram maior peso de abate que os animais castrados (Tabela 3) devido ao maior ganho de peso no período de confinamento observado pelos animais não castrados. Restle et al. (1994), Ítavo et al. (2008) e Andreo et al. (2013) observaram que animais não castrados apresentam maior peso de abate e carcaça quente, resultados estes que corroboram com os valores apresentados. Assim, os animais não castrados podem atingir o peso de abate mais rapidamente, podendo reduzir o tempo de confinamento e consequentemente o custo de produção.

Os animais não castrados se mostraram mais eficientes quando comparados aos castrados, em relação ao ganho GMD, consumo de alimento, CA e RC. Não foi observado durante o experimento problemas relacionado ao comportamento dos animais não castrados quanto à agressividade ou de sodomia.

Houve efeito significativo para a espessura de gordura subcutânea (EGS), sendo que os animais castrados apresentaram maior espessura de gordura que os animais não castrados 
(Tabela 3). Os animais castrados foram mais eficientes na deposição de gordura subcutânea que os animais não castrados. Entretanto, os animais não castrados apresentaram EGS dentro dos padrões que são exigidos pela indústria frigorífica que é de 3 a $6 \mathrm{~mm}$ de EGS. O que pode ter favorecido para que os animais não castrados tenham depositado gordura subcutânea favorável seria a dieta alto grão devido a sua composição de nutrientes (Tabela 1) apresentando teores de extrato etéreo (EE) e nutrientes digestíveis totais (NDT) na dieta de $4,77 \%$ e $84,39 \%$, respectivamente.

Kuss et al. (2009) avaliando a espessura de gordura de animais abatidos aos 26 meses recebendo dietas com 50\% de volumoso (silagem de milho) e $50 \%$ de concentrado encontraram valores de 4,72 e $2,90 \mathrm{~mm}$ para animais castrados e não castrados, respectivamente. A dieta alto grão propiciou que os animais não castrados depositassem gordura na carcaça (Tabela 3) o que pode estar correlacionado aos teores de NDT da dieta.

Os animais não castrados apresentaram maior receita bruta, maior custo por animal, porém maior lucro por animal, o que proporcionou maior retorno quando comparado aos animais castrados (Tabela 4).

Tabela 4. Custo de aquisição e viabilidade da terminação de bovinos Nelore, castrados e não castrados, terminados em confinamento recebendo dieta alto grão

\begin{tabular}{|c|c|c|c|c|}
\hline \multirow{2}{*}{ Variável } & \multicolumn{2}{|c|}{ Classe sexual } & \multirow{2}{*}{$\mathrm{CV}$} & \multirow{2}{*}{$\mathrm{P}$} \\
\hline & Castrado & Não castrado & & \\
\hline Aquisição dos animais $(\mathrm{R} \$)$ & $1.389,42$ & $1.420,27$ & 19,60 & 0,975 \\
\hline Receita bruta $(\mathrm{R} \$)$ & $1.822,80$ & $1.917,30$ & 9,52 & 0,001 \\
\hline Receita - Aquisição (R\$) & 433,38 & 497,03 & 5,82 & 0,001 \\
\hline Custo da dieta/boi/período (R\$) & 230,58 & 241,92 & 4,19 & 0,001 \\
\hline Custo da dieta/boi/dia (R\$) & 3,66 & 3,84 & 4,19 & 0,001 \\
\hline Margem de lucro/boi (R\$) & 202,80 & 256,00 & 4,19 & 0,001 \\
\hline
\end{tabular}

Os dados da Tabela 4 corroboram com o trabalho de Lopes et al. (2008), em que estudaram o efeito do ganho de peso na rentabilidade em confinamento. Os autores constataram que o custo que mais interfere é a aquisição dos animais seguido dos custos com a alimentação, e observaram que o lucro foi maior quando o GPD foi de $1,3 \mathrm{~kg}$. Desta forma, o ganho de peso influência no custo operacional efetivo do confinamento.

Lopes et al. (2005) analisaram comparativamente, por meio de simulação, a rentabilidade da terminação de bovinos de corte castrados e não castrados e consideraram que os GMD dos animais não castrados foram superiores aos castrados e concluíram que a prática da castração influenciou negativamente o custo total de produção da arroba de carne. Porém, os autores relataram que o frigorífico penalizou os animais não castrados em $\mathrm{R} \$ 2,00$ por arroba, devido a isso a lucratividade e rentabilidade dos castrados foram satisfatórias. Isso não foi observado, pois os animais não castrados apresentaram EGS que atende as exigências do frigorífico (Tabela 3 ).

O pecuarista pode optar por confinar animais não castrados com ganhos de peso superiores a $16,7 \%$ que animais 
castrados, o que proporcionaria maior rentabilidade utilizando animais não castrados (LOPES et al., 2005). Os animais castrados e não castrados, apresentaram lucro, porém os animais não castrados foram superiores demonstrando maior eficiência no sistema de terminação em confinamento recebendo dieta alto grão (Tabela 4). Ítavo et al. (2008) concluíram que animais não castrados apresentam maior margem líquida e lucratividade, tanto por animal como por área, quando comparados a animais castrados em sistemas de produção de carne, no entanto as características de carcaça não permitem a comercialização no mesmo valor pago para a arroba do boi.

A carne bovina e o milho são commodities agrícolas, e sofrem influência do mercado externo, sendo assim vulnerável a variação de preço, por isso, a compra do milho em relação ao valor da arroba paga ao produtor, são fatores determinantes a viabilidade do sistema. Logo, sua aquisição requer uma atenção à época do ano e suas sazonalidades, para que se possa atingir a maior margem de lucro possível.

Um dos benefícios observados com a utilização do confinamento como estratégia de manejo na propriedade seria em retirar os animais na fase de terminação do pasto, o que possibilita aumentar a disponibilidade de forragem para as outras categorias do rebanho, aumentando a taxa de lotação e consequentemente o giro de capital.

Os animais não castrados podem ser utilizados na obtenção de carcaças de qualidade, desde que abatidos jovens e com condições nutricionais suficientes para depositarem gordura na carcaça, o que foi observado no uso da dieta alto grão, que proporcionou acabamento nos bovinos machos Nelore não castrados terminados em confinamento.
Recomenda-se a terminação de novilhos Nelore em confinamento recebendo dieta alto grão. Os animais castrados apresentaram maior espessura de gordura subcutânea que animais não castrados. Os animais não castrados apresentaram maior ganho de peso e lucro no sistema de terminação em confinamento recebendo dieta alto grão.

\section{REFERÊNCIAS}

ANDREO, N.; BRIDI, A.M.; TARSITANO, M.A.; PERES, L.M.; BARBON, A.P.A.C.; ANDRADE, E.L.; PROHMANN, P.E.F. Influência da imunocastração (Bopriva $\left.{ }^{\circledR}\right)$ no ganho de peso, características de carcaça e qualidade da carne de bovinos Nelore. Semina:Ciências Agrárias, v.34, n.6, p.4121-4132, 2013.

\section{CAPELLE, E.R.; VALADARES}

FILHO, S.C.; DA SILVA, J.F.C.; CECON, P.R. Estimativas do consumo e do ganho de peso de bovinos, em condições brasileiras. Revista

Brasileira de Zootecnia, v.30, n.6, p.1857-1865, 2001.

FIELD, R.A. Effect of castration on meat quality and quantity. Journal Animal Science, v.32, p.849-857, 1971.

ÍTAVO, L.C.V.; DIAS, A.M.; ÍTAVO, C.C.B.F.; EUCLIDES FILHO, K.; MORAIS, M.G.; SILVA, F.F.; GOMES R.C.; SILVA, J.P.B. Desempenho produtivo, características de carcaça e avaliação econômica de bovinos cruzados, castrados e não-castrados, terminados em pastagens de Brachiaria decumbens. Arquivo Brasileiro de Medicina Veterinária e Zootecnia, v.60, n.5, p.1157-1165, 2008. 
Rev. Bras. Saúde Prod. Anim., Salvador, v.17, n.1, p.45-54 jan./mar., $2016 \quad$ http://www.rbspa.ufba.br ISSN 15199940

KUSS, F.; LOPEZ, J.; BARCELLOS, J.O.J.; RESTLE, J.; MOLETTA, J.L.; PEROTTO, D. Características da carcaça de novilhos não-castrados ou castradosterminados em confinamento e abatidos aos 16 ou 26 meses de idade. Revista Brasileira de Zootecnia, v.38, n.3, p.515-522, 2009.

LOPES, M.A.; SANTOS, G.; ROSA, L.V. LOPES, N.M. Rentabilidade da terminação em confinamento de bovinos de corte castrados e não castrados.

Boletim de Indústria Animal, v.62, n.4, p.289-294, 2005.

LOPES, M.A.; SANTOS, G.; MAGALHÃES, G.P.; LOPES, N.M. Efeito do ganho de peso na rentabilidade da terminação em confinamento de bovinos de corte. Revista Brasileira de Agrociência, v.14, n.1, p.135-141, 2008.

MARCONDES, M.I.; VALADARES FILHO, S.C.; PAULINO, P.V.R.; DETMANN, E.; PAULINO, M.F.; DINIZ, L.L.; SANTOS, T.R. Consumo e desempenho de animais alimentados individualmente ou em grupo e características de carcaça de animais Nelore de três classes sexuais. Revista Brasileira de Zootecnia, v.37, n.12, p.2243-2250, 2008.

McDONALD, P.; EDWARDS, R.A.; GREENHALGH, J.F.D.; MORGAN, C.A.; SINCLAIR, L.A.; WILKINSON, R.G. Animal Nutrition. 5th. ed.

Singapore: Longman, 1995. 607p.

MISSIO, R.L.; BRONDANI, I.L.; ALVES FILHO, D.C.; SILVEIRA, M.F.; FREITAS, L.S.; RESTLE, J.

Comportamento ingestivo de tourinhos terminados em confinamento, alimentados com diferentes níveis de concentrado na dieta. Revista Brasileira de Zootecnia, v.39, n.7, p.1571-1578, 2010.
NATIONAL RESEARCH COUNCIL NRC. Nutrient Requirements of Beef Cattle. 7 ed. Washington D.C.: National Academy Press, 1996. 242 p.

OBEID, J.A.; PEREIRA, O.G.; PEREIRA, D.H; VALADARES FILHO, S.C.; CARVALHO, I.P.C.; MARTINS, J.M. Níveis de Proteína Bruta em Dietas para Bovinos de corte: consumo, digestibilidade e desempenho produtivo. Revista Brasileira de Zootecnia, v.35, n.6, p.2434-2442, 2006.

PAULINO, P.V.R.; VALADARES FILHO, S.C.; DETMANN, E.; VALADARES, R.F.D.; FONSECA, M.A.; MARCONDES, M.I. Deposição de tecidos e componentes químicos corporais em bovinos Nelore de diferentes classes sexuais. Revista Brasileira de Zootecnia, v.38, n.12, p.2516-2524, 2009.

RESTLE, J.; FLORES, J.L.C.; VAZ, F.N.; LISBOA, R.A. Desempenho em confinamento, do desmame ao abate aos quatorze meses, de bovinos inteiros ou castrados, produzidos por vacas de dois anos. Ciência Rural, v.27, p.651-655, 1997.

RESTLE, J.; GRASSI, C.; FEIJÓ, G.L.D. Evolução do peso de bovinos de corte inteiros ou castrados em diferentes idades. Pesquisa Agropecuária Brasileira, v.29, p.1631-1635, 1994.

SILVA, D.J.; QUEIROZ, A.C. Análise de alimentos: métodos químicos e biológicos. 3. ed. Viçosa, MG: Universidade Federal de Viçosa, 2002, $235 p$. 
SILVA, F.V.; ROCHA JÚNIOR, V.R.;

BARROS, R.C.; PIRES, D.A.A.;

MENEZES, G.C.C.; CALDEIRA, L.A.

Ganho de peso e características de carcaça de bovinos Nelore castrados ou não-castrados terminados em confinamento. Revista Brasileira de Zootecnia, v.37, n.12, p.2199-2205. 2008.

VALADARES FILHO, S.C.; PAULINO, P.V.R.; MAGALHÃES, K.A. Exigências nutricionais de zebuínos e tabelas de composição de alimentos BR Corte. Viçosa, MG:

Universidade Federal de Viçosa, 2006. $142 p$.

Data de recebimento: $12 / 08 / 2014$

Data de aprovação: 22/02/2016 